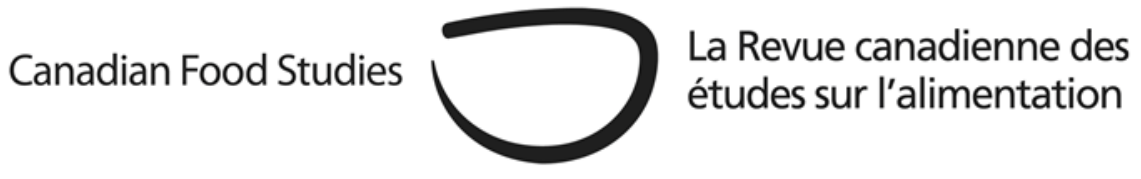

Original Research Article

\title{
Seed saving in Atlantic Canada: Sustainable food through sharing and education
}

\author{
Norma Jean Worden-Rogers $^{\mathrm{a}^{*}}$, Kathleen Glasgow ${ }^{\mathrm{b}}$, Irena Knezevic ${ }^{\mathrm{a}}$, Stephanie Hughes ${ }^{\mathrm{c}}$ \\ ${ }^{\text {a }}$ Carleton University \\ ${ }^{\mathrm{b}}$ St Francis Xavier University \\ ${ }^{\mathrm{c}}$ Atlantic Canada Program Coordinator for the Bauta Family Initiative on Canadian Seed Security, SeedChange
}

\begin{abstract}
Seed saving can support seed security, biodiversity, nourish food systems, facilitate environmental education, and enable the creation of networks that support food sovereignty. Public interest in seed security is on the rise, but local resources and funding to support seed activities is limited. The survival of seed collections, libraries, banks, and farms depends on personal relationships within the seed community. While Atlantic Canada's seed saving community is scattered geographically, it is tightly knit. Seed savers share knowledge, information, and tools, sometimes between competitor businesses. At times, information is shared between those with commercial interests, such as seed companies, and public events such as seed swaps, because an individual seed-saver's success is contingent on the overall health of the seed system. In this paper, we synthesize findings from three case studies on seed saving in Atlantic Canada, which map regional seed activities, and detail the opportunities and challenges that such initiatives face. While Atlantic Canada has seen growth in the number and scale of both public and private seed saving initiatives, much work remains to be done. Nevertheless, the initiatives constitute a critical mass that can benefit from this assessment upon which future actions can be based.

In conjunction with this article, we produced a video that highlights the work of seed-savers in Atlantic Canada. You can find this video, Supporting Seed Saving and Farmers in Atlantic Canada, at https://www.youtube.com/watch?v=7jAmS-jXOYs
\end{abstract}

*Corresponding author: normajeanwr@gmail.com

DOI: $10.15353 /$ cfs-rcea.v6i3.352 
Keywords: seeds; seed saving; seed conservation; seed security; Atlantic Canada; sustainable food systems; social economy; informal economy

Introduction

Seed saving "should be understood to encompass the myriad of activities... including the growing, collection, storage, reuse, and/or exchange of seeds (and/or other propagating material)" as well as "the generation and maintenance of the necessary knowledge and networks for seed saving practices to occur" (Phillips, 2005, p. 39). Although the vast majority of food comes from seed ${ }^{1}$, this paper aims to contribute to broader literature that considers the social life of seed - the role that human networks, relationships and cultural practices play in the selection, transmission, and conservation ${ }^{2}$ of seeds (Ellen \& Platten, 2011).

The research synthesized in this paper comprised three case studies that explored seed saving in Atlantic Canada ${ }^{3}$. Each of the authors was involved with the development of at least one of the case studies. The three studies document seed activities in the region to identify how those activities contribute to food production, and also to food system resilience, the well-being of rural communities, and regional social capital. While the case studies were based on different research questions and varied geographic focus, many of their findings were strikingly similar. Hence, we reflect on what we learned through those three studies and go beyond the original, mostly descriptive, reports to offer a more analytical view of how these activities align with the economic, environmental, and social contributions of sustainable food systems.

The resulting paper offers a portrait of regional seed activities and links seed saving to key aspects of social economy of food and its contribution to community development and resilience. We demonstrate that despite the environmental heterogeneity of Atlantic Canada, the seed community in this region is characterized by relationships that facilitate sharing of knowledge, information, and tools - in many cases with competitor businesses, because individual success is linked to the health of the seed system as a whole. Our findings further

\footnotetext{
${ }^{1}$ About three-quarters of the human energy intake comes from some 120 plants that are cultivated for food (UNFAO, n.d.).

2 "Seed conservation" is commonly used by those who work in more technical settings, like seed libraries, and it can imply a more complex and deliberate approach than just "saving" seed. Though some in the seed world distinguish saving from conservation, other use the terms interchangeably as both approaches contribute to seed security.

${ }^{3}$ The case studies were funded by the Social Sciences and Humanities Research Council through two grants administered by the Laurier Centre for Sustainable Food Systems. Whereas this funding played a crucial role in enabling the research activities, these studies are a result of numerous partnerships, and are also a product of support (both financial and in-kind) from Seeds of Diversity Canada, Atlantic Canada Organic Regional Network, and The Bauta Family Initiative on Canadian Seed Security.
} 
suggest that seed conservation can contribute to the key elements of social economy, namely: bridging divides, building adaptive capacity, increasing prosperity, increasing social capital, and fostering innovation and entrepreneurship (Blay-Palmer et al., 2019).

We conclude that the diversity and quality of seeds are challenged by a variety of factors that are often place-specific and therefore require place-specific solutions. Existing solutions tend to be grass-roots and, in Atlantic Canada, are characterized by an enthusiastic, diverse seedsaving community; nevertheless, to continue the seed-savers contributions to community, organized and institutional support is necessary to sustain them in the long term, through continuous funding, research, facilities, and seed literacy.

Background: The art of seed-saving

Seed saving is fundamental to achieving local and global seed security, which can be defined as having access to adequate quantities of good quality seed and planting materials of preferred crop varieties at all times (UNFAO, 2015).

Since the introduction of commercial hybrid seeds in the 1930s, plant breeding and seed production have become commodified, which has had an impact on the diversity of seeds that are favoured by the agri-food industry, and has had social consequences (Kloppenburg, 2004). Through extensive international "development" projects in the mid- $20^{\text {th }}$ century, the process often referred to as the "Green Revolution", a concerted effort was led by plant scientists and development agencies in the United States to promote technological solutions (including hybridized seed) at the expense of local knowledge and practices (Esteva, 1996). The technologies of Green Revolution also encouraged constant enlargement of farm-size and management of the farm as a business (Kneen, 1995). Concurrently, public plant breeding programs started to erode and the private sector came to dominate the development of new seed (Kuyek, 2004), which has undermined seed sovereignty - understood to include "rights to save, breed and exchange seeds, to have access to diverse open source seeds which can be saved" (Gopalan, 2018, p. 257). The resulting commercial varieties came to rule the seed economy, with troubling consequences to local food production and rural economies in both the global South and the global North (Kloppenburg, 2004). Over the past century 75 percent of the global agricultural biodiversity has disappeared and this means seed security is at risk (UNFAO, 1999). This threat is compounded by climate change; without diverse genetics underlying seed systems there is a reduced ability for crop varieties to respond to novel climatic conditions (Agriculture and Agri-Food Canada, 2016).

Still, parallel practices of seed saving have continued (Carolan, 2011; Phillips, 2013) in ways that "may offer ways of living that are vitally different from those presented through neoliberal, corporate orderings" (Phillips, 2013, p. 5). Global seed conglomerates like Syngenta, DowDupont, Bayer, and BASF dominate the commercial markets, especially for patented seed (Howard, 2015), but tend to do so with a focus on a selection of cash-crops with limited genetic 
diversity emphasizing just a handful of traits - USC Canada suggests that " 95 percent of the seeds that grow our major food crops are bred for uniformity, performance under controlled conditions and routine application of synthetic inputs" (2017, para. 5). Most smaller actors in the seed sector, however, display an impressive diversity in practices and variety of seed, as will become apparent in the rest of this report.

Collaborative or cooperative seed distribution models (e.g., the Organic Seed Alliance in the United States, BC Eco Seed Co-op in Canada) are becoming more common in the sector. Consequently, some researchers identify seed saving as part of social economy of food (Nelson \& Stroink, 2011), where social economy refers to collective economic activities for which economic benefits are only one of, and often not the primary, set of motives. In other words, social economy is an organizing principle that encompasses a wide range of activities and values (McMurtry, 2008) and seed saving is among those activities. Moreover, many seed saving interactions take place in the informal economy realm (where there is no monetary exchange) and are explicitly positioned as a resistance to the commodification of seed-a "repossession" that relocates seeds in the commons (Patnaik, Jongerden and Ruivenkamp, 2017). Seed exchange networks are vibrant around the world and "help to conserve agricultural, social, cultural diversity, and identity as well as enhance resilience against environmental and economic shocks" (Helicke, 2015, p. 638). In non-industrialized countries, reliance on commercial seed is minimal, and farmers procure upwards of 90 percent of all their seed through such networks (Coomes et al., 2015; McGuire \& Sperling, 2016). Seed exchange remains an "important, yet poorly understood, factor shaping agrobiodiversity and helping its dynamic conservation" (Pautasso et al., 2013). The informal nature of much seed exchange is not in itself unproblematic; Coomes et al. (2015) detail the various ways in which social relations can create friction and suggest that although there is no monetary transaction in informal seed exchanges, those who exchange seed still recognize that the seed has economic value. Still, seed exchange networks are persistent and are likely to remain so (Coomes et al., 2015) and they can greatly facilitate social relationships within networks (Ellen \& Platten, 2011).

As we discovered in Atlantic Canada, these informal relationships can further be promoted by research and community projects that encourage seed saving, exchange, and development of seed collections. Various organizations play a role here including seed banks, seed libraries and seed companies (see Table 1).

Table 1: Seed organization types

\begin{tabular}{|l|l|}
\hline Organization type & Organization function \\
\hline Seed banks (and gene banks) & $\begin{array}{l}\text { Plant material is placed in short- and long-term storage with the intention of preserving } \\
\text { the genetics of the species or variety. }\end{array}$ \\
\hline Seed libraries & $\begin{array}{l}\text { Focused on seed education and awareness where anyone can "borrow" small quantities } \\
\text { of seed, grow them out and return them to the library if successful. }\end{array}$ \\
\hline
\end{tabular}




\begin{tabular}{|l|l|}
\hline $\begin{array}{l}\text { Local (or regional) seed } \\
\text { companies }\end{array}$ & $\begin{array}{l}\text { Commercial entities that provide larger quantities of seed predominantly grown in the } \\
\text { region, but are significantly smaller than the conglomerates that dominate the } \\
\text { commercial seed market; the companies identified in our case studies provide varieties } \\
\text { of that are non-hybridized, and are locally and sustainably grown; they sell seed they } \\
\text { grow themselves, contract from local growers, or utilize some combination of this; } \\
\text { occasionally they source seed further afield to fill out a catalogue. }\end{array}$
\end{tabular}

Unique microclimates throughout Atlantic Canada make locally adapted seed important but unique challenges for seed security are presented by the geographic, economic and social landscape as is further discussed in our analysis. Despite being geographically disparate, seed savers in Atlantic Canada remain a tightly knit community working to educate and engage the public, and to save and exchange seed.

\section{Methods}

This paper synthesizes three related qualitative case studies that were conducted in Atlantic Canada in 2015 and 2016 and each resulted in a published report (Glasgow, Hughes \& Knezevic, 2016; Jamieson, Hughes \& Knezevic, 2016; Worden-Rogers, 2015). These studies explored aspects of seed saving such as project models, relationships between stakeholders, successes and challenges, and gaps in existing activities. Each case study was developed by drawing on literature reviews (of grey and scholarly publications), environmental scans, and interviews.

Figure 1: The geographic context and populations of each province in Atlantic Canada. Population estimates from census data (2014)
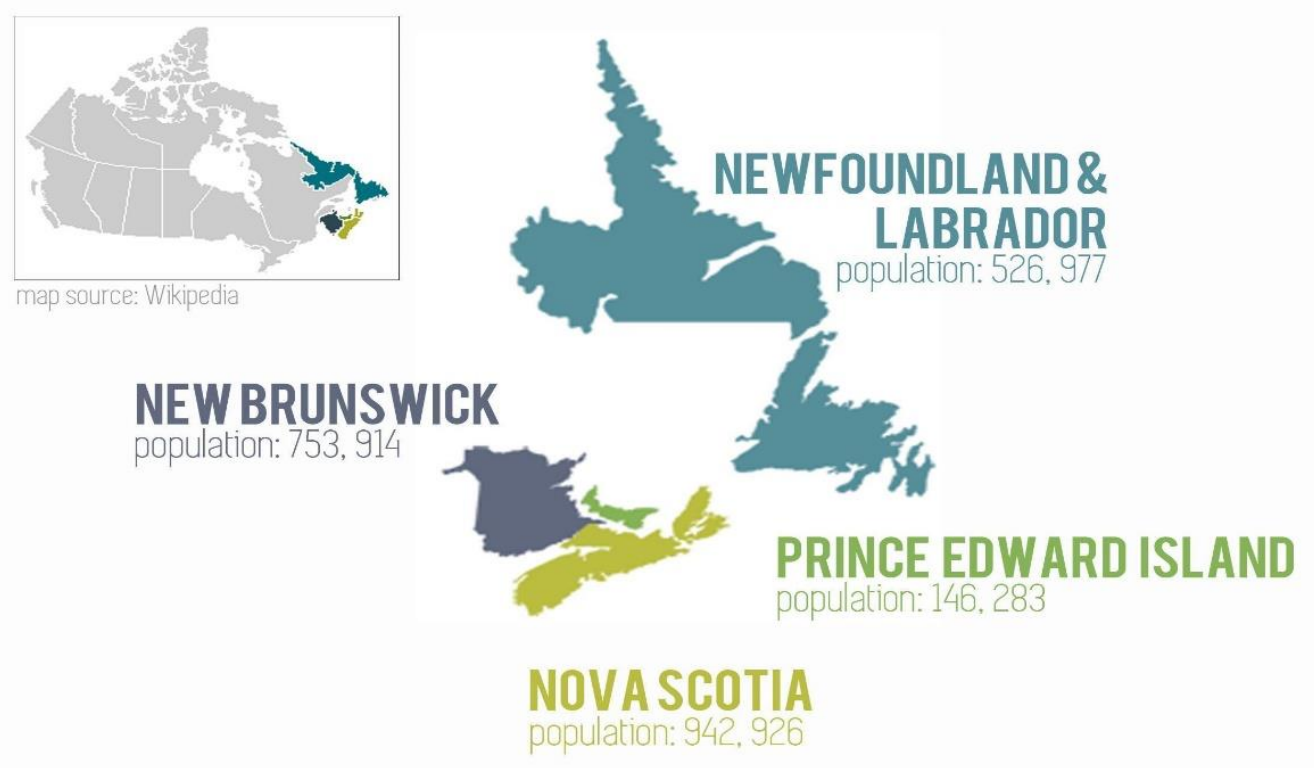

Source: Worden-Rogers, 2015 
The research team encompassed community and academic researchers. Two community researchers were already working on regional seed saving initiatives and were regularly conducting research for their organizations. Academic researchers comprised both faculty (two faculty members, one in sciences and one in social sciences) and three students. The literature reviews included non-scholarly reports published by governments and non-profit organizations. The environmental scans involved searches for relevant organizations and initiatives in the region; simple web searches formed the basis of each scan, and then scans were expanded using information found in organizational directories, identified in local media reports, and-later on in the projects_-provided by interviewees. Both the literature reviews and environmental scans were guided by the researchers' prior knowledge of regional seed conservation activities, and advice from regional seed experts. The interviews supplemented this information and assisted in interpreting the findings. A total of 26 interviews were conducted across the studies ${ }^{4}$. Interview participants included seed savers, seed producers, and representatives from seed organizations including seed company owners, seed researchers, and community organizers involved with seed activities. Obviously, some participants fall into more than one of these categories. Interviews were semi-structured, conducted by phone or in person, and lasted between 30 and 90 minutes. The case studies' findings were reported in narrative form, accompanied by maps, tables and images (Glasgow, Hughes \& Knezevic, 2016; Jamieson, Hughes \& Knezevic, 2016; Worden-Rogers, 2015).

Figure 2: Interviews by province and respondent type

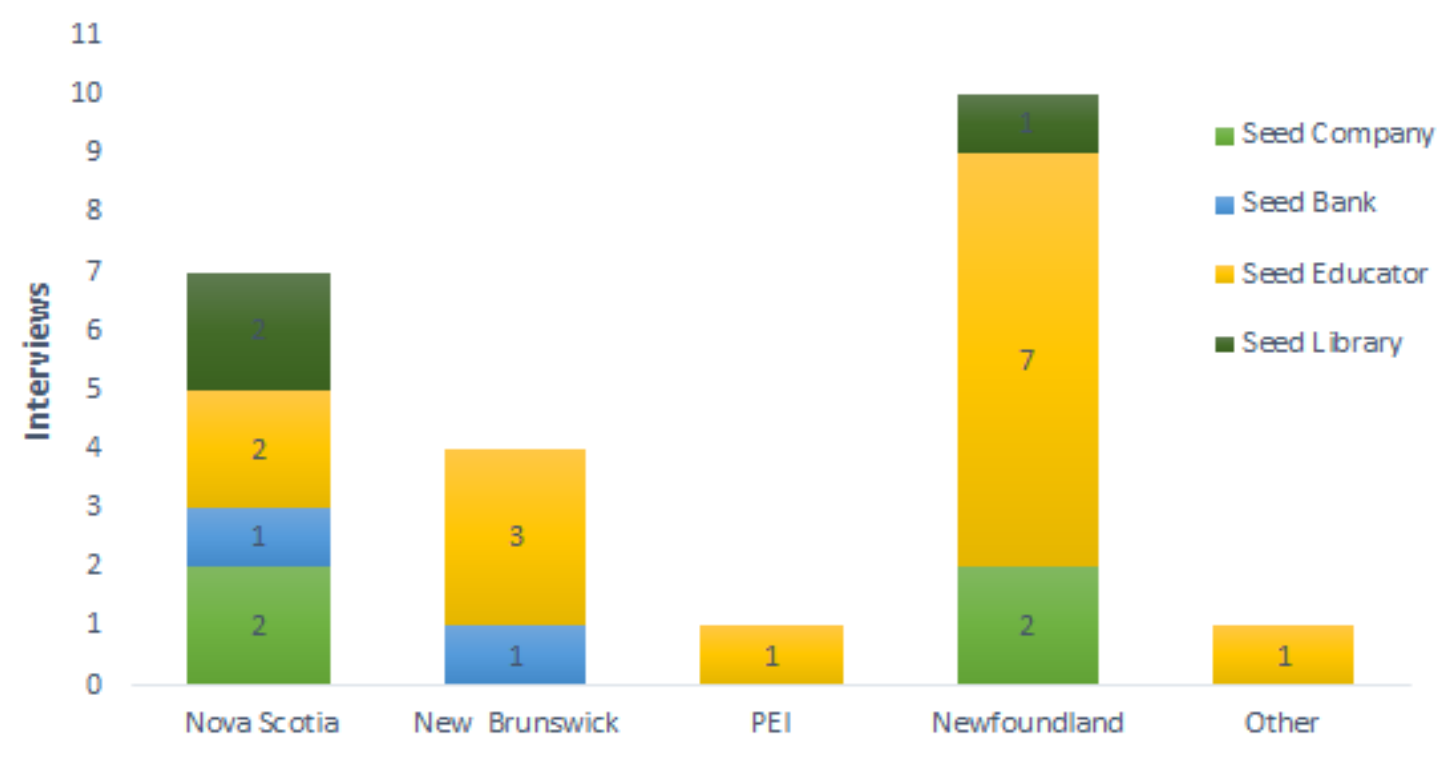

${ }^{4}$ All research methods were approved by the Carleton University Research Ethics Board. 
Those findings were analyzed for commonalities as we revisited the case study reports and discussed our observations to decide on the key conclusions. Original transcripts and field notes were also revisited to guide our analysis. The observations were organized thematically and then analyzed against the guiding questions of the larger project on the social and informal economy of food (Stephens et al., 2019) to assess if and how the seed activities contributed to food system sustainability (see Discussion).

\section{Findings}

Our findings provide insights into the regional seed conservation context, key motivations for seed saving, adaptive capacity, seed literacy, scale, infrastructure, and collaboration. We describe these findings below.

\section{Context}

The momentum of seed saving is recently on the upswing in Atlantic Canada. Seeds of Diversity (SOD) is the key national organization supporting seed saving; it has representatives in every province, and provides organizational support by hosting events, workshops, organizing seed viability maintenance (grow-outs) and funding. The Bauta Family Initiative on Canadian Seed Security (The BFICSS) is a national initiative to increase the diversity, quantity and quality of seeds grown in Canada and is delivered in the region by the Atlantic Canada Organic Regional Network (ACORN). The BFICSS also supports seed saving in a variety of ways, including funding, organizational, and educational capacities as well as funding and physical infrastructure. In 2014, the Dalhousie University Faculty of Agriculture in Truro, Nova Scotia, partnered with The BFICSS and SOD to host Atlantic Canada's first Regional Seed Bank. Storage, maintenance of quality and distribution can be the most expensive aspect of seed conservation and by having a central seed bank, with lab facilities required to test seed quality, accessibility and capacity to save seed is significantly increased.

\section{Key motivations}

Since the three studies engaged a breadth of individuals involved in the seed saving sector (Figure 2), the reasons that individuals saved seed varied; however, there were several commonly repeated reasons, as summarized in Table 2.

Table 2: The reasons for seed saving cited by interviewees 


\begin{tabular}{|l|l|}
\hline Reasons & Number of respondents \\
\hline Promote education through skill sharing & 9 \\
\hline Assurance of viability of seed & 4 \\
\hline Save 'tried and true' varieties & 9 \\
\hline Increase/maintain biodiversity & 11 \\
\hline Cost-effectiveness & 7 \\
\hline
\end{tabular}

The key motivations for seed saving loosely map onto the relationship the interviewee had with seed saving. For example, the educational programs cited seed education as paramount; community gardens and seed companies are interested in the value of seed with more weight given to the ecological and economic aspects of regional seed saving. Participants also identified local issues of seed security (especially in Newfoundland, where growing conditions are harsher). The most commonly cited motivation was the desire to maintain and increase biodiversity.

Participants generally did not believe each province studied here needed seed banks, suggesting that the single existing seed bank Truro, Nova Scotia, is sufficient as a central repository, as long as it is accompanied by a healthy number of seed libraries and seed-exchange events. While the interaction of seed and gene banks with other seed entities could be expanded to develop a stronger relationship (e.g., with seed companies to better preserve seeds of lower commercial interest), the concurrent proliferation of seed libraries seemed to compensate for that gap.

Bob Wildfong, Executive Director of Seeds of Diversity Canada, confirmed the notion that seed banks collect small quantities of many varieties, while the role of seed libraries was to

...fulfill the desire [of] communities to take control of their seed sources. They're not efficient at providing large quantities of high quality seed, tested seed like seed companies are, but they are much more accessible to people and give a way for people to get actively involved in their community, and connects seed savers (Glasgow, Hughes \& Knezevic, 2016).

\section{Adaptive capacity and place-specific seed varieties}

Every seed is the family bible and history of the plant - the amount of information that's packaged in a single seed is extremely significant.

-Will Bonsall, The Scatterseed Project (Worden-Rogers, 2015)

Seed saving in Atlantic Canada is treated as an art -- mindfully passed from individual to individual and motivated largely by biodiversity preservation. Genetic diversity is one of the first factors in biological adaptive capacity, and given the diverse growing conditions in Atlantic 
Canada, is one of the most heavily referenced seed saving benefits. Building adaptive capacity has both social and biological dimensions. A community's ability to recover from natural disasters or shifting markets is a form of adaptive capacity. The term is also a key concept in environmental science and evolutionary biology, where it refers to the ability of an organism or system to modify to suit a new environment (McCouch et al., 2013). This is particularly relevant with the loss of agricultural biodiversity cited above, amplified here by the many microclimates in Atlantic Canada and impending climate change.

Across the Atlantic region, stakeholders acknowledged the need to rebuild adaptive capacity to promote seed resilience and biodiversity, but this theme was most prominent in Newfoundland. Seeds are saved because most commercial seed is not adapted to excel in Newfoundland's unique and harsh climate. The majority of mainstream (eg. industrial) seed distributors are located in mainland Canada and they distribute seed produced all over the globe. They tend to see high-production regions as their target market, paying less attention to marginal production areas.

While a seed that is produced in southern Ontario may not thrive in New Brunswick, it should still grow and produce. This is not always the case for Newfoundland. Due to the harsh winters, short growing season, and climatic differences, Newfoundland-specific varieties are much favoured over imported varieties, but they are in short supply as one entire generation had virtually stopped cultivating Newfoundland-specific varieties. Contemporary seed saving runs counter to this loss of seed literacy and proliferation of hybrid seeds of the past few decades and is both a necessity and an act of self-sufficiency and resilience.

\section{Seed literacy}

For a plant to adapt to a new environment a wide variety of traits must be present in the plant's genes, even if they are not expressed or useful in the conditions under which it has historically grown. For the purpose of this paper, a plant includes both annual and perennial seeds. The majority of grow outs were intended to be organic, however due to the lack of education amongst growers, it could not be guaranteed that seed saving would yield "true" types. Some participants suggested that with genetic erosion of place-based seed varieties, traits that were previously irrelevant, but may become desirable in novel conditions, are lost.

Some participants questioned if seed libraries were sometimes compromising the genetic integrity of varieties. Within the context of seed libraries and seed banks, perhaps the most stringent guidelines for seed production (that specify distance between individual plants in grow outs, for example) care are used by the Atlantic Canada's Regional Seed Bank, developed by SOD. The guidelines and continued documentation of seed saving are prioritised to preserve genes for future research and use. But not all seed entities are as stringent about the seeds they accept. Since education is crucial to seed security, inconsistencies can lead to barriers in both seed quality and education. Some more experienced seed savers expressed concern about 
"scruffy" seed that is produced by new seed savers and is exchanged in organizations like seed libraries, viewing their contribution to Atlantic Canada's seed security as minimal. This perspective was offset by recognition of learning as a process and the view that the contribution of these "scruffy" seeds goes far beyond just their genetics. The community building and seed literacy that develop within groups of new seed savers are also valuable, though efforts to ensure seed quality should not be dismissed.

Seed libraries tend to be largely community run and ... are springing up all over the place, and I think that's just fine, they are educational tools and we are not expecting them to change the seed system. What we are expecting them to do is improve people's understanding and engagement with the seed system.

Michelle Smith, seed saver and educator (Glasgow, Hughes \& Knezevic, 2016)

As Smith's statement suggest, the concern about "scruffy" seeds and the conviction that seedsaving can contribute to food security are not necessarily contradictory. Instead, these comments point out that the more experienced seed savers appreciate the ongoing seed saving efforts, and also see areas where those efforts can be improved.

\section{Infrastructure}

Every movement with food has an analogous movement with seed; people started talking about food security, then five years later began to talk about seed security. Local food movements lead to the local seed movements.

Bob Wildfong, seed educator (Glasgow, Hughes \& Knezevic, 2016)

Fuelled by a bottom-up approach, seed education gives individuals the knowledge required to save seed and has resulted in a blossoming of such activities in the region. It is common to learn about informed individuals sharing knowledge and facilitating activities in the form of a summer program or a seasonal plot at a community garden. The growth of regional seed activities can thus be credited to the growing community participation, however, there are both strengths and limitations of a seed system built from the bottom up as seed communities depend heavily on personal relationships. These relationships mean recruitment and training of new seed savers often occurs in an informal and place-based manner, allowing newcomers to learn to save seed as a part of a community. This place-and people-based system is also consistent with the motivations for seed saving in Atlantic Canada and demonstrates an appreciation for the uniqueness of communities, in both climate and culture. The relationships among and between individuals and organizations give the seed movement resilience.

However, these relationships alone are insufficient to maintain the momentum required for regional seed security. There is a point where the demands on the most active community 
members become too great and require a larger organization to take on some of the administrative burden and retain momentum. Seed educators tend to wear several hats and are often involved in various projects with different funding sources. These individuals become the driving forces behind their regional seed saving practices. As with other forms of community food work (see, for example, Knezevic, Mount \& Clement, 2016), there is also significant pressure on the committed seed "champions" who become victims of their own success. The more they share their knowledge and passion, the greater the pressure on them to maintain momentum. When seed programs are underfunded, these champions risk burnout.

Moreover, as is often the case with grassroots initiatives, when seed saving activities grow, seed programs encounter funding limitations. The current funding landscape has facilitated growth, but it often means numerous funding applications must be completed throughout the calendar year, each requiring many hours of labour. The challenge to find resources for seed projects is compounded by the highly seasonal nature of the allotted funding. While there are a few funding opportunities, they tend to be for short-term projects and the monetary value is generally not enough to support even a part-time or seasonal employee. Though seed saving may be considered a seasonal activity, the associated institutional work of supporting regional seed security — such as, establishing and nourishing partnerships and delivering education-is yearround work. Many projects are only able to hire during the peak season, and during this time finding future funding, or planning future years are not priorities - the seeds themselves are, and this can cause instability in projects. Without the funding to support this development many of the groups within the seed saving community are barely making it season to season, let alone planning ahead for the longer term.

Formal entities such as the Atlantic Canada Regional Seed Bank, SOD, ACORN, and partners such as The BFICSS have played a critical role in growing the momentum and overcoming the cited barriers of the bottom-up approach. In fact, this was a primary motivation of The BFICSS to inject energy and resources into the national seed movement to give it a boost toward self-sustainability. In complementing the grassroots movement, the organizations facilitate seed activities without being disruptive to the wider movement. In other words, the organizations support activities that are complementary to ongoing efforts of the movement, while ensuring they are not competing with pre-existing initiatives and events. The barriers are addressed through actors in seed conservation connecting with larger institutions and organizations to provide coordinated support. Examples of this are the Regional Program Coordinator position with $\mathrm{ACORN}^{5}$ that connects the various stakeholders in the sector; the Atlantic Canada Regional Seed Bank provides a well-equipped physical space for saved seed; Salem Elementary School Coordinator is a paid position which utilises outdoor space on a pilot outdoor education program, and so on. These roles also bridge the rural-urban divide to promote seed security through a variety of means, despite their success being limited by the

\footnotetext{
${ }^{5}$ This position is also a result of organizational collaboration, as the position is with ACORN, and supported by the BFICSS and SOD.
} 
available funding.

This integration of grassroots activities within the institutional framework works well, although it requires entities to play different roles. Seed banks can archive, protect and maintain diverse seed stocks as well as document the progression of the wider seed-saving efforts through communication and events. The contribution of unstructured seed saving, and sharing is significant to the overall seed security of a region and may often be more attainable. Enhancing communication pathways can streamline conservation efforts while ensuring that at-risk varieties are not missed, and that new varieties that thrive under specific climatic conditions are developed. All of these observations suggest that incorporating seed saving activities into work of larger organizations can be beneficial for grassroots work too, as long as the organizations are willing to collaborate and support ongoing initiatives, rather than compete with or replace them.

\section{Collaborative approach}

Despite the potential of commercial gain, seed savers in this region generally tend to act in partnership with one another, favouring collaboration over competition -- even in cases where they own a seed company or sell seed from their farm. In addition to the grassroot-institutional collaboration noted above, partnerships permeate, and make possible, the seed conservation in the region. A consistent theme of seed saving is to retain local varieties of seed-place-based varieties adapted to local environmental and social conditions. This is an activity that must be collectively supported to be successful.

This collaborative culture is reinforced by the deeply embedded tradition of co-operatives in the region (MacPherson, 1975). The Cumberland County Ecological Seed Growers Cooperative (CCESGC) is one example of a cooperative that came together informally in 2014 to share local knowledge and assist one another in the provision of seed security - a collaboration between famers who rely on seeds to support their livelihoods. The farmers were located in one geographic region, so the growing conditions were similar. In sharing their knowledge, the farmers not only supported one another but also created equipment to assist in the gleaning of the seed harvest. This instrument, created by observation and innovation, was then shared between the farmers to increase their efficiency.

[T] he partnerships with these organizations and colleague seed savers from the area [were essential]. It was helpful in terms of providing training and networking, personalized guidance and motivation ([from] the two coordinators. My colleague seed savers from the Amherst shore have been helpful in testing my seeds and giving me feedback.

Silvana Castillo, La Finquita Seeds and member of CCESGC (Worden-Rogers, 2015)

The groups that see environmental education as their core purpose act as a kind of cooperative as these groups tend to have land. The availability of land is the biggest asset and the first requirement for conducting seed saving activities. Whether that be as a school and they have 
excess land, or a community garden allowed district land to be used for community growing. One example of this is Salem Elementary School in Sackville, New Brunswick. The school now has a year-round environmental education class that integrates food growing into the curriculum, a forerunner in this aspect of environmental education. During the school closure over the summer, the school partners with the Sackville Community Garden and their coordinator (typically funded by a summer government grant), provides weekly sessions to continue the education-based learning. Previously, in the months leading up to the summer holiday, the children would be exposed to the planting and growing of the seed but would return in the autumn to find the food was already harvested or had decomposed to the point that saving the seed would not be possible. This partnership allows the children to have an opportunity to understand the entire lifecycle of a plant and makes a contribution -- small, but not negligibleto the community's social, economic and environmental wellbeing.

Many students were excited to bring these activities home and seed save with their parents/families. The students have now saved their own seeds which we will plant next spring in the school gardens ...they can observe the entire lifecycle of a plant. Josette MacIssac, Outdoor Education Teacher, Salem Elementary School (WordenRogers, 2015)

Discussion: Seed saving as social economy of food

My own interest in saving seeds [links] a sustainable system, and [my] interest in local food for a long time...the seeds are kind of like the missing link [in food security]. You can grow all your own food, but if your seeds are coming from somewhere you don't even know...that's kind of a link in the food security chain that's slowly become in the public awareness. And with the interest in local food, there is a growing interest in local seeds as well. That movement is already in the works in NS.

Chris Sanford, Representative, Bridgetown seed library (Glasgow, Hughes and Knezevic, 2016)

Seed saving activities in Atlantic Canada offer unique insights into the social and informal dimensions of food systems. These activities demonstrate that productive collaborations can and do exist among private, public and community sectors. They connect local initiatives with regional, and even national, efforts - from local seed exchange events to SOD. Each province is faced with similar issues surrounding regional food security and the popularity of local food as a route to sustainability is growing. As communities adopt a bottom-up approach, with grassroots efforts to build seed security, larger organizations serve as the linchpin to provide infrastructure and funding, maintain seed stocks, and document seed activities over a long-term period. As identified in these studies, though communication pathways could be enhanced between entities 
like the seed bank and seed libraries/savers, all actors play integral roles in the Atlantic Canadian seed and food system.

The case studies suggest that the momentum of regional seed saving has the potential to transgress social divides, as such activities don't have to be limited by income or rural/urban location. Of course, like any activity, seed saving requires resources (time, knowledge, space), but access to seed libraries is free, and there is no money exchanged at seed exchange events. Moreover, the rise in urban and peri-urban agriculture is slowly challenging the long-standing position of food production as an exclusively rural practice. That said, it remains unclear how inclusive the current seed work in this region has been. We know, for instance, that community seed gardens in Cumberland County, Nova Scotia, have been explicitly involving low-income neighbourhoods, seniors' residences, and other marginalized groups, but it is difficult to know how sustainable these initiatives will be in the long run.

We also know that there are efforts on the ground to revive "three sisters" gardenswhere corn, beans, and squash grow together - as an Indigenous practice in this region, and these efforts are taking place in First Nations communities and other public places (for example, the University of Prince Edward Island campus). These efforts acknowledge the seed saving tradition among the region's First Nations, but otherwise little has been documented about this practice, and further research on this topic would be beneficial.

The case studies show that seed savers wish to maintain and improve biological diversity through seed saving by building the adaptive capacity of the regional food system. Despite small disparate populations, unfavourable growing conditions and accessibility of services that can support seed saving (e.g. due to geographic distance), Atlantic Canada's seed saving community appears to have an extensive adaptive capacity based on the development of a network that values the conservation of seed.

Regional seed saving offers the ability to strengthen social prosperity - through seed education at various institutional levels (e.g., from kids' day camps to universities) — and ecological prosperity, by saving seed from varieties that may otherwise be lost. The case studies indicate that saving seed that thrives in a particular area supports the ecological suitability of the variety, and it creates an economic niche if the seed saver has a commercial enterprise. Several case study participants indicated that, while economical, the cost efficiency is not the overall determining factor for saving seed. The physical availability and viability of the seed is the resounding benefit, fostering a material manifestation of intertwined social, environmental and economic prosperity.

The very nature of seed saving is to preserve biodiversity, save local seed varieties and share skills (thus fostering community). However, at the core of each of these themes is social interaction, which educates and then drives the participants to continue seed saving activities in a perpetual resource and skill sharing. The activities documented here encourage collaboration over competition, adding to social capital. Social capital, which refers to "the set of norms, networks, and organizations through which people gain access to power and resources" (Grootaert, 1998, p. 2) can be "bonding" (within social groups) and "bridging" (across social 
groups). Whereas both are seen as crucial to community development (Woodhouse, 2006) the case studies in question document that seed conservation can contribute to bridging social capital by connecting a variety of actors across public and private sectors.

While seeds are owned by the various actors in this network (savers, companies, libraries, etc.) they also contribute to the shared benefits of biodiversity. Communities can and do manage resources in the common interest and to their common benefit (Ostrom, 2010). If actors communicate with and/or know each other, their desire to preserve the common resources is greater and encourages cooperation and sustainability, as opposed to competition and resource exploitation (Ostrom, 2010).

Finally, the case studies suggest that seed saving can play a role in fostering innovation and entrepreneurship. Sharing knowledge can stimulate innovative seed saving methods and allow for solutions to be found more quickly than if activities were done in a competitive context. Cooperation is key to this sharing. While there were formal cooperatives in this sector (e.g., CCESGC), community groups such as community gardens or educational gardens also offer a platform for cooperation.

\section{Conclusions}

Seed conservation is a critical component of food security and biodiversity. Atlantic Canada boasts a growing number of seed initiatives, which tend to be grass-roots, and characterized by an enthusiastic, diverse seed-saving community. The sector is propped up by motivated individuals, supportive institutions and funding entities, and a collaborative approach to pursuing common goals of seed diversity and adaptive capacity. Our analysis confirms what other studies have found - that community seed networks can make significant contributions to biodiversity conservation (Coomes et al., 2015) and at the same time both facilitate and are facilitated by social interaction (Ellen \& Platten, 2011).

The vitality of this sector, along with the diversity and quality of seeds it conserves, is challenged by a variety of factors that are often place-specific and therefore require placespecific solutions. To ensure that seed-savers continue to contribute to the overall community well-being, it is necessary to strengthen organized, institutional support through continuous funding, research, facilities, and seed literacy. Improved communication pathways (e.g., between the seed banks and seed savers) are also critical to avoid redundancy and determine what seeds are important to maintain or even develop.

Acknowledgements: We wish to thank research participants and community partners who helped with these projects, and to Shelby Jamieson for her assistance with this research. We are also indebted to the late Su Morin who was the driving force behind much of this work. 


\section{References}

Agriculture and Agri-Food Canada. (2016). Canada's seed industry. Retrieved from http://www.agr.gc.ca/eng/industry-markets-and-trade/statistics-and-marketinformation/by-product-sector/crops/pulses-and-special-crops-canadian-industry/canadas-seed-industry/?id=1174596024742

Blay-Palmer, A., Knezevic, I., Levkoe, C.Z., Mount, P., \& Nelson, C. (2019). Introduction to the special issue on the social and informal economy of food. Canadian Food Studies, this issue.

Carolan, M. (2011). Saving Seeds, Saving Culture: A Case Study of a Heritage Seed Bank. Society and Natural Resources, 20(8), 739-750.

Coomes, O.T., McGuire, S.J., Garine, E., Caillon, S., McKey, D., Demeulenaere, E... Wencélius, J. (2015). Farmer seed networks make a limited contribution to agriculture? Four common misconceptions. Food Policy, 56, 41-50.

Ellen, R., \& Platten, S. (2011). The social life of seeds: the role of networks of relationships in the dispersal and cultural selection of plant germplasm. Journal of the Royal Anthropological Institute, 17(3), 563-584.

Glasgow, K., Hughes, S., \& Knezevic, I. (2016). Mapping Nova Scotia's seed collection systems. Waterloo, ON: Centre for Sustainable Food Systems. Retrieved from https://fledgeresearch.ca/resources-results/mapping-nova-scotias-seed-collections-system.

Esteva, G. (1996) Hosting the otherness of the other: The case of the Green Revolution. In F. Apffel-Marglin, \& S.A. Marglin, (Eds.), Decolonizing Knowledge (pp. 249-278). Oxford: Oxford Press Online.

Gopalan, R. (2018). Food sovereignty: The future of food. In K. Bhushi (Ed.), Farm to fingers: The culture and politics of food in contemporary India (pp. 236-268). Cambridge: Cambridge University Press.

Grootaert, C. (1998). Social capital: The missing link? Social Capital Initiative Working Paper, Washington: World Bank Social Development Program. Retrieved from http://siteresources.worldbank.org/INTSOCIALCAPITAL/Resources/Social-CapitalInitiative-Working-Paper-Series/SCI-WPS-03.pdf

Helicke, N.A. (2015), Seed exchange networks and food system resilience in the United States, Journal of Environmental Studies and Sciences, 5, 636-649.

Howard, P. H. (2015). Intellectual property and consolidation in the seed industry. Crop Science, $55,1-7$.

Jamieson, S., Hughes, S., \& Knezevic, I. (2016). Considerations for seed security and biodiversity conservation in Newfoundland. Waterloo, ON: Centre for Sustainable Food Systems. Retrieved from https://fledgeresearch.ca/resources-results/considerations-forseed-security-and-biodiversity-conversation-in-newfoundland/ 
Kloppenburg, J. R. (2004). First the seed: The political economy of plant biotechnology. Madison: University of Wisconsin Press.

Kneen, B. (1995). From land to mouth: Understanding the food system (2nd ed.). Toronto: NC Press Ltd.

Knezevic, I., Mount, P., \& Clement, C. (2016). Shared opportunities on institutional land: Improving health care environments through on-site food production. HERD: Health Environments Research \& Design Journal, 10(1), 144-154.

Kuyek, D. (2004). Stolen seeds: the privatization of Canada's agricultural biodiversity. Sorrento, BC: Ram's Horn.

MacPherson, I. (1975). Patterns in the maritime co-operative movement 1900-1945. Acadiensis, $5(1), 67-83$.

McCouch, S., Baute, G. J., Bradeen, J., Bramel, P., Bretting, P. K., Buckler, E., \& Zamir, D. (2013). Feeding the future. Nature, 499, 23-24.

McGuire, S., \& Sperling, L. (2011) The links between food security and seed security: facts and fiction that guide response. Development in Practice, 21 (4-5), 493-508.

McMurtry, J.J. (Ed.). (2008). Living economies: Perspectives on Canada's social economy. Toronto: Edmond Montgomery Publications.

Nelson, C., \& Stroink, M. (2011). Working paper: Food security and sovereignty. Montreal: Chantier de l'économie sociale. Retrieved from https://idl-bnc-idrc.dspacedirect.org/.

Ostrom, E. (2010). Beyond markets and states: Polycentric governance of complex economic systems. American Economic Review, 100, 1-33.

Patnaik, A., Jongerden, J., \& Ruivenkamp, G. (2017). Repossession through sharing of and access to seeds: different cases and practices. International Review of Sociology, 27(1), 179-201.

Pautasso, M., Aistara, G., Barnaud, A., Barnaud, A., Caillon, S., Clouvel, P.,.. Tramontini, S. (2013). Seed exchange networks for agrobiodiversity conservation. A review. Agronomy for Sustainable Development, 33, 151-175.

Phillips, C. (2005). Cultivating practices: Saving seed as green citizenship? Environments, 33(3), 37-49.

Phillips, C. (2013). Saving more than seeds: Practices and politics of seed saving. New York: Routledge.

Stephens, P., Knezevic, I., \& Best, L. (2019). Community financing for sustainable food systems: The case of FarmWorks Investment Co-operative. Canadian Food Studies, this issue.

Stephens, P., Nelson, C., Levkoe, C.Z., Mount, P., Knezevic, I., \& Martin, M. A. (2019). A perspective on social economy and food systems: Key features insights and thoughts on future research. Canadian Food Studies, this issue. 
.UNFAO. (1999). What is happening to agrobiodiversity. Food and Agriculture Organization of the United Nations. Retrieved from http://www.fao.org/docrep/007/y5609e/y5609e02.html.

UNFAO. (2015). Household seed security concepts and indicators. Food and Agriculture Organization of the United Nations. Retrieved from http://www.fao.org/fileadmin/user_upload/food-security-capacitybuilding/docs/Seeds/SSCF/Seed_security_concepts_and_indicators_FINAL.pdf

UNFAO. (n.d.). Seeds of life. Retrieved from http://www.fao.org/3/x0262e/x0262e02.htm

USC Canada. (2017). The Bauta family initiative on Canadian seed security. Retrieved from https://www.usc-canada.org/what-we-do/the-bauta-family-initiative-on-canadian-seedsecurity

Woodhouse, A. (2006). Social capital and economic development in regional Australia: A case study. Journal of Rural Studies, 22, 83-94.

Worden-Rogers, N. J. (2015). Seed saving in Atlantic Canada. Waterloo, ON: Centre for Sustainable Food Systems. Retrieved from http://nourishingontario.ca/the-socialeconomy-of-food/seed-saving-in-atlantic-canada/ 